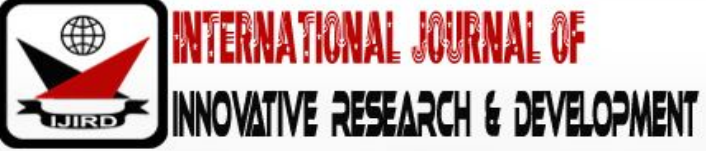

ISSN 2278 - 0211 (Online)

\section{Competitive Strategies and Technological Capabilities among Malaysian Manufacturing Organization: Empirical Evidence from Malaysia}

D. Sasitharan
Ph.D. Student, School of Technology Management and Logistic,
University Utara Malaysia, Malaysia
Halim Mad Lazim
Associate Professor, School of Technology Management and Logistic,
University Utara Malaysia, Malaysia

\begin{abstract}
:
The current unforeseen global economic environment constantly challenges the sustainability of Malaysian manufacturing organization. The primary objective of this study is to explore deeper understanding in clarify the role of competitive strategies and its impact on organizational performance. By using the quantitative research technique and cross-sectional research design, total 200 questionnaires were distributed among the managers and engineers of manufacturing firms. This study employed Smart PLS 3 software to analyze collected the data. The results of study show that competitive strategies have significant positive influence to enhance organizational performance. Moreover, this study also found that technological capabilities significantly moderate the relationship between competitive strategies; (Cost leadership; Differentiation; Focus) and organizational performance (Cost; Quality; Flexibility Delivery).
\end{abstract}

Keywords: Organizational performance, competitive strategies, technological capabilities, competitive advantage

\section{Introduction}

In the current era of industrialization, the Malaysian manufacturing sector is one of the key drivers that extensively contribute to the growth of Malaysian economy. As an evidence, the Bank Negara Malaysia (BNM) stated that Malaysia manufacturing sector contributed to the national economy through extending the external trades and vast creation of new job opportunities to the Malaysians (Bank Negara Malaysia 2016). This claimed also supported by Hooi and Leong (2017), according to him huge number of job vacancies had been offered by manufacturing sectors as compared to other sectors such as agriculture and services that drive the consistence growth of Malaysia economy.

The vision of Malaysian government up to 2050 is to recognize the development of blue print and performance of manufacturing firms for up-scaling (Ahmad \& Ahmad, 2015; Aun, 2017). Although most of the Malaysian manufacturing firms adopting various policies to improve the productivity growth (Stuckler, Reeves, Karanikolos \& McKee, 2015). However, there are contradicted views from several numbers of studies that focused on manufacturing performance. For instance, Stuckler, et al, (2015), Hasan et al., (2016) and Jomo (2013) revealed numerous evidences which shows that the Malaysia manufacturing firm still unable to cope with global competitions especially their neighbor countries.

Therefore, Wahab, Ismail \& Muhayiddin (2016) emphasizedin order to have se efficiency and effective manufacturing process all Malaysian firm must take step to move forward by understand factors that stabilize the companies to global competition by adopting proactive techniques that offer efficiencies in production and profit margin. In addition, Monemi et al., (2015), and Singh \& Ahuja (2017) emphasized that it is essential for manufacturing companies to adopt proactive approaches to overcome the production failures that directly or indirectly affect manufacturing performance. Hence, it is important to identify the importance to identify what are the main role of competitive strategies in Malaysian manufacturing the that enhance the sustainable technological capabilities that boost organizational performance among Malaysian manufacturing.

Based on issue above this study proposed there research objective that will used as research gap that investigate by empirically to answer the question of; how theeffective competitive strategies to enhance organizational performance. To examine the effect of cost leadership strategy on organizational performance.

- To examine the effect of differentiation strategy on organizational performance.

- To examine the effect of focus strategy on organizational performance.

- To examine the moderating role of technological capabilities between competitive strategies and organizational performance. 


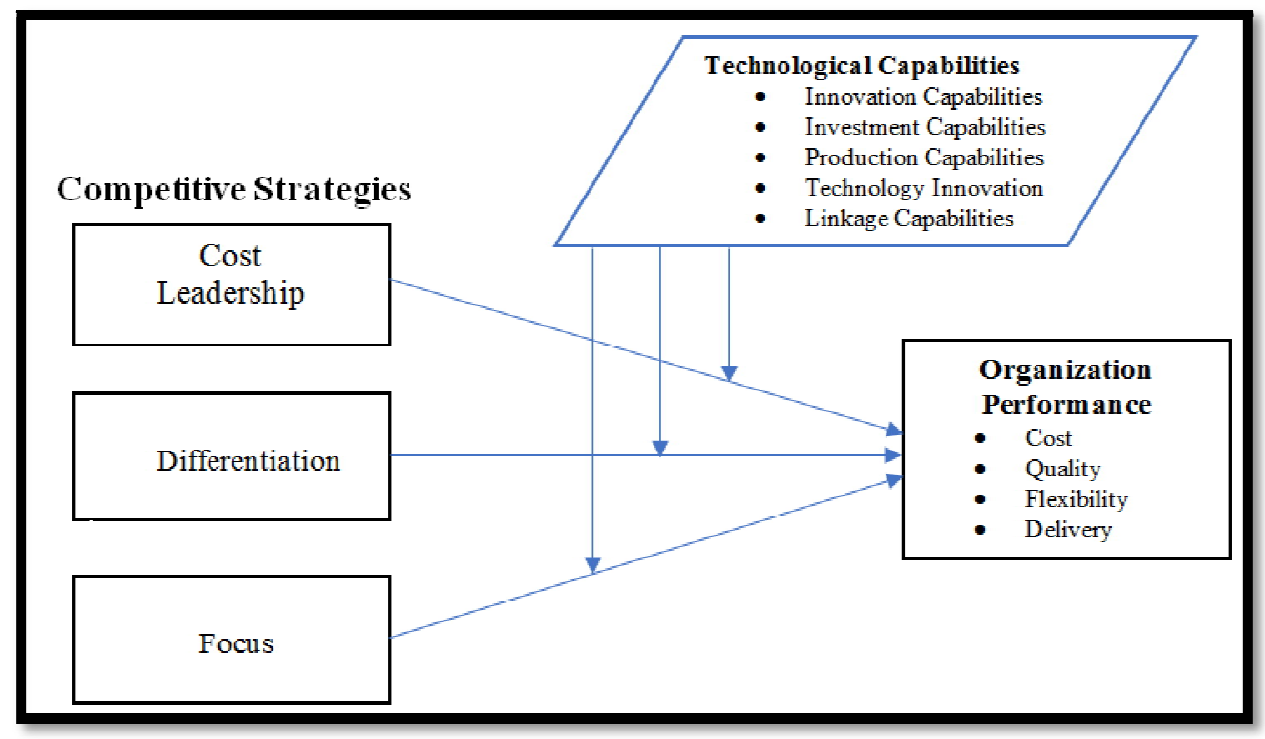

Figure 1: Theoretical Framework

\subsection{Hypotheses}

- H1: Cost leadership has significant relationship with organizational performance.

- H2: Differentiation has significant relationship with organizational performance.

- H3: Focus has significant relationship with organizational performance.

- H4: Technological capabilities moderates the relationship cost leadership and organizational performance.

- H5: Technological capabilities moderates the relationship differentiation and organizational performance.

- H6:Technological capabilities moderates the relationship focus and organizational performance.

\section{Literature Review}

The findings of Scherer \& Palazzo (2012) claimed from most of the business studies that stressed the tangible or intangible factor effect the performances of organization and strongly associated with firm achievement. There are several studies argued that performance of an organization could be identify based on the productivity of organizations, profitability market shares and satisfaction of customer (Bayer, Tuli \& Skiera, 2017 and Mithas \& Rust, 2016). By referring to the statements of Dangelico, Pontrandolfo \& Pujari (2013), Maistry and Hurreeram, (2017), the optimum performance of firms can be achieved by enhancing some fictional competencies (e.g. designing or installing new products or production technologies, adapting well-skilled programmers, embracing the quality control methods and improving the ties among suppliers) that could be act as essentials factors for consistent improvement that will indirectly influence the performance of corporation. In the similar tone, Calantone, Cavusgil, and Zhao (2002) also have been pointed that the most important impacts d in most organization is innovativeness thatsignificantly contribute to the success of firm performance.

The study conducted by Hill \& Hill (2017) indicated the low-cost manufacturing should be the main concern if the profit margin is low. The reason to associate the leadership-cost approach to competitive advantage as based on suggestion from Porter (1991) is due to the competitive advantage can be categorized into lesser cost than competitors and the capability togive a more efficient system which to distinguish with high success rates that promise premium price that surpass the additional costs of doing so. Typically, quality known as a competitive instrument of the market. As has been stated by Kazan, Ozer \& Cetin (2006) quality has been define through various perspectives as the subjective and objective has indefinable characteristics. On other hand, Mandelbaum (1978) defined the flexibility as the efficient system that enable organizations need and capability to understand effectively to impact consumer satisfaction in any circumstances. A large number of scholars have been extended and agreed on the flexibility importance to cope with vagueness of flexibility (Schwager, Haack \& Taha, 2014; Challagalla, Murtha \& Jaworski, 2014; Tjader, May, Shang, Vargas $\&$ Gao, 2014). The similarities in the definitions of flexibility referred to the major job that mastered the changes and faced uncertainty outcomes via internal and external environment of business. Delivery is another competitive priority due to much concern on satisfying customer needs and deliver right quantity at predefined time. In the point of the view, Kumar \& Kumar (2006) explained that "delivery of the required function referred to the activities to make sure that the right product that meet the quality, maintainability and reliability requirements to delivered at correct quantity time, place, and sources. Differentiation focus in understand factors that differentiating consumer understanding to the product or service that the organization to the stabilization stage. Simply, it could be said as developing a product or service that is perceived as unique in industry-wide. There are many directions to achieve differentiation, for instance, byusing design, technology, brand image etc. (Miltenburg, 2005).

Technological capabilities known as an ability of an organization to develop and utilize technologies in order to manufacture new products more effectively and efficiently than their challengers particularly related with organization capability to use and apply technology in the initiative of new products such as assessment on preliminary technical, development of prototype, pilot production, and start- up of production (Yalcinkaya, Calantone, \& Griffith 2007). Investment capability is described as the skills as well as information required to recognize feasible investment projects (Xue Liang et al., 2008). Production capability is known as the skills and knowledge that drive firm manufacturing 
operation of the production facilities. Production capability determinants of new information or technologythat consequently lead to two different stage. First Pre-investment and the second was Project execution under the investment capability that has been completed (Biggs, 1999). Furthermore, innovation in technology is also most important which effect positively on organization performance. Innovation is the formation of value redirect to capabilities and information required by every firm to detect feasible investment projects (Madanmohan, Kumar, et al., 2004).

\section{Research Method}

This paper employed quantitative approach in collect data were cross-sectional research design were used to collect the data among selected focus group. The population of this study was purposely focus on organizational level. The respondent of this study was Malaysia manufacturers situated throughout the Peninsular Malaysia and each company will send one questionnaire to express their opinion on answer the research gap on. According to Malaysian Industry Development Authority (MIDA) basically Malaysia has two main sector it was service and manufacturing. Moreover the manufacturing sector was divided into two main types of industries: First resource-based and second non-resource-based industries (MIDA, 2016). This study only focuses toward manufacturing related sector that includes resource-based and non-resource-based industries respondents who operate in Malaysia. As mentioned earlier the focus of this study is organizational level and the representative of the manufacturing companies can be managers as well as various engineers that directly contributed with manufacturing plant operation and has more than 3 years' experience in this field. There were total 200 questionnaires were distributed via postal letter; fax and email.

\section{Data Analysis and Results}

\subsection{Measurement Model Assessment}

Before the structural analysis (hypothesis testing) was conducted the measurement model was examined to measure the reliability of data. Hair et al, (2016) pointed that it is mandatory to test structural model by measure the: composite reliability; Cronbach alpha; factor loading that must above 0.7. Table 1 shows that all the factor loading value for; (CL); (DIFF); (FOC); (OP); (TC) is more than 0.7. Moreover the Average variance extracted (AVE) value also $p>0.5$ in rage of $0.745-0.828$ which confirms convergent validity at satisfactory level.

\begin{tabular}{|c|c|c|c|c|c|}
\hline Construct & Indicators & Loadings & Cronbach Alpha & Composite Reliability & AVE \\
\hline Cost leadership (CL) & $\begin{array}{l}\text { CL1 } \\
\text { CL2 } \\
\text { CL3 } \\
\text { CL4 }\end{array}$ & $\begin{array}{l}0.879 \\
0.914 \\
0.937 \\
0.908\end{array}$ & 0.931 & 0.950 & 0.828 \\
\hline Differentiation (DIFF) & $\begin{array}{l}\text { DIFF1 } \\
\text { DIFF2 } \\
\text { DIFF3 } \\
\text { DIFF4 }\end{array}$ & $\begin{array}{l}0.794 \\
0.935 \\
0.946 \\
0.939\end{array}$ & 0.925 & 0.948 & 0.820 \\
\hline Focus (FOC) & $\begin{array}{l}\text { FOC1 } \\
\text { FOC2 } \\
\text { FOC3 } \\
\text { FOC4 }\end{array}$ & $\begin{array}{l}0.884 \\
0.918 \\
0.892 \\
0.902\end{array}$ & 0.921 & 0.944 & 0.808 \\
\hline $\begin{array}{c}\text { Organizational } \\
\text { performance (OP) }\end{array}$ & $\begin{array}{l}\text { OP1 } \\
\text { OP2 } \\
\text { OP3 } \\
\text { OP4 } \\
\text { OP5 }\end{array}$ & $\begin{array}{l}0.923 \\
0.855 \\
0.909 \\
0.824 \\
0.919\end{array}$ & 0.932 & 0.949 & 0.787 \\
\hline $\begin{array}{c}\text { Technological } \\
\text { capabilities (TC) }\end{array}$ & $\begin{array}{l}\text { TC1 } \\
\text { TC2 } \\
\text { TC3 } \\
\text { TC4 }\end{array}$ & $\begin{array}{l}0.849 \\
0.847 \\
0.888 \\
0.869\end{array}$ & 0.886 & 0.921 & 0.745 \\
\hline
\end{tabular}

Table 1: Factor Loading, Reliability, Convergent Validity, Ave

\subsection{Structural Model Assessment}

\begin{tabular}{|c|c|c|c|c|c|c|c|}
\hline Hypotheses & Relationship & $\begin{array}{c}\text { Original } \\
\text { Sample (0) }\end{array}$ & (M) & (STDEV) & T Statistics & P Values & Decision \\
\hline H1 & CL -> OP & 0.230 & 0.238 & 0.108 & 2.121 & 0.034 & Supported \\
\hline H2 & DIFF - > OP & 0.212 & 0.220 & 0.104 & 2.037 & 0.042 & Supported \\
\hline H3 & FOC - > OP & 0.454 & 0.435 & 0.110 & 4.137 & 0.000 & Supported \\
\hline \multicolumn{7}{|c|}{ Table 2: Direct Hypotheses Results }
\end{tabular}

Table 2 indicates the results of inner model in which all the direct hypotheses without moderation were tested. Overall result indicate the P-value of $\mathrm{H} 1 ; \mathrm{H} 2$ and $\mathrm{H} 3$ show $\mathrm{p}<0.05$ thus all hypotheses was accepted. 


\begin{tabular}{|c|c|c|c|c|c|c|c|}
\hline Hypotheses & Relationship & $\begin{array}{c}\text { Original } \\
\text { Sample (0) }\end{array}$ & (M) & (STDEV) & $\begin{array}{c}\text { T } \\
\text { Statistics }\end{array}$ & $\begin{array}{c}\text { P } \\
\text { Values }\end{array}$ & Decision \\
\hline H4 & $\begin{array}{c}\text { CL - > TC } \\
->\text { OP }\end{array}$ & 0.324 & 0.343 & 0.122 & 2.664 & 0.010 & Supported \\
\hline H5 & $\begin{array}{c}\text { DIFF - TC } \\
->\text { OP }\end{array}$ & 0.215 & 0.199 & 0.095 & 2.259 & 0.028 & Supported \\
\hline H6 & $\begin{array}{c}\text { FOC - > TC } \\
->\text { OP }\end{array}$ & 0.841 & 0.801 & 0.178 & 4.725 & 0.000 & Supported \\
\hline
\end{tabular}

Table 3: Moderation Effect

Table 3 demonstrates the moderation results. Moreover, 1.96 minimum level of $\mathrm{t}$-value was considered to accept or reject the hypothesis direct and moderation hypotheses. Hair et al., (2016) stated the significance level to accept the hypothesis is should be equal to or less $(\mathrm{p}<0.05)$. From all the direct effect, it is clear that the moderation analysis for $\mathrm{H} 4$; $\mathrm{H} 5$ and $\mathrm{H} 6$ show that all relationships have $t$-value more than $(\mathrm{t}>1.96)$ and $\mathrm{p}$-value below $(\mathrm{p}<0.05)$. Moreover, it is also clear from Table 3 Therefore, this study declare that all the hypotheses $(\mathrm{H} 1 ; \mathrm{H} 2 ; \mathrm{H} 3 ; \mathrm{H} 4 ; \mathrm{H} 5 ; \mathrm{H} 6)$ are accepted.

\section{Discussion}

After analyzing the data, it is found that competitive strategies have significant positive relationship with organizational performance in Malaysian manufacturing firms. Good competitive strategies are essential to maintain a good performance in Malaysian manufacturing firms. Thus, improvement in competitive strategies will directly improve the performance. It is found that cost leadership has significant impact in enhancing external factors in boosting Malaysian organizational performance. It can be found from the direct hypothesis result which show the p-value 0.034 and t-2.121. The $\mathrm{p}$-value is significant for relationship with $\beta$-value 0.230 . Thus, cost leadership variable show has positive significant relationship with organizational performance. In the same direction, differentiation and focus strategy has positive significant relationship at $(\mathrm{p}<0.042)$ with organizational performance with $\mathrm{p}<0.000$ respectively. The $\beta$-value is 0.212 and 0.454 respectively. Additionally, it is clear that technological capabilities (TC) successfully moderate toward both independent and dependent variables it was competitive strategies (CS) and organizational performance (OP). These can be found from moderation effect between cost leadership and organizational performance is significant with $p$-value 0.010 , t-value 2.664 and $\beta$-value 0.324 .

\section{Conclusion}

As conclusion, this study declares that competitive strategies (CS) and technological capabilities (TC) are successfully show significant relationship in gaining competitive advantage in boosting Malaysian manufacturing performance. These competitive strategies are needed to achieve a better performance and generate the competitive advantage among Malaysian manufacturing organizations. This study suggests that; to improve the organizational performance every organization in Malaysia must design interventional programs that can enhance the positive effect of competitive strategies that can be supported by enhancing the technological capabilities. It is recommended forauthorsto extent the knowledge of this by adopt various approach such as; supply chain; information technology; innovative Human Resource practices; total quality management; Just-in-Time; Total Productive Maintenance; computer-aided manufacturing to examines its relationships with firm performance.

\section{Reference}

i. Ahmad, S. Z., Abu Bakar, A. R., Faziharudean, T. M., \& Mohamad Zaki, K. A. (2015). An empirical study of factors affecting e-commerce adoption among small-and medium-sized enterprises in a developing country: Evidence from Malaysia. Information Technology for Development, 21(4), 555-572.

ii. Aun, L. H. (2017). Malaysia's Transformasi Nasional 2050 Brings Bold New Style, but to What End?

iii. Bank Negara Malaysia. (2016). Malaysia manufacturing sector contributed to GDP.

iv. Bayer, E., Tuli, K. R., \& Skiera, B.,. (2017). Do Disclosures of Customer Metrics Lower Investors' and Analysts' Uncertainty but Hurt Firm Performance?. Journal of Marketing Research, 54(2), 239-259.

v. Calantone, R. J., Cavusgil, S. T., \& Zhao, Y.,. (2002). Learning orientation, firm innovation capability, and firm performance. Industrial Marketing Management, 31(6), 515-524. .

vi. Challagalla, G., Murtha, B. R., \& Jaworski, B.,. (2014). Marketing doctrine: a principles-based approach to guiding marketing decision making in firms. Journal of Marketing, 78(4), 4-20. .

vii. Dangelico, R. M., Pontrandolfo, P., \& Pujari, D., . (2013). Developing sustainable new products in the textile and upholstered furniture industries: role of external integrative capabilities. Journal of Product Innovation Management, 30(4), 642-658. .

viii. Hair Jr, J. F., Hult, G. T. M., Ringle, C., \& Sarstedt, M. (2016). A primer on partial least squares structural equation modeling (PLS-SEM): Sage Publications.

ix. Hasan, H. (2016). A Study on Awareness and Perception Towards Halal Foods among Muslim Students in Kota Kinabalu, Sabah. Proceedings of the Australia-Middle East Conference on Business and Social Sciences 2016, Dubai, 803-811..

x. Hill, T. (2017). Manufacturing strategy: the strategic management of the manufacturing function: Macmillan International Higher Education.

xi. Hooi, L. W., \& Leong, T. Y. (2017). Total productive maintenance and manufacturing performance improvement. 
Journal of Quality in Maintenance Engineering, 23(1), 2-21.

xii. Jomo, K. S. (2013). Industrializing Malaysia: policy, performance, prospects: Routledge.

xiii. Kazan, H., Özer, G., \& Tansel Çetin, A. (2006). The effect of manufacturing strategies on financial performance. Measuring Business Excellence, 10(1), 14-26.

xiv. Kumar, S., Massie, C., \& Dumonceaux, M. D. (2006). Comparative innovative business strategies of major players in cosmetic industry. Industrial Management \& Data Systems, 106(3), 285-306.

xv. Madanmohan, T., Kumar, U., \& Kumar, V.,. (2004). Import-led technological capability: a comparative analysis of Indian and Indonesian manufacturing firms. Technovation, 24(12), 979-993.

xvi. Miltenburg, J. (2005). Manufacturing strategy: how to formulate and implement a winning plan: CRC Press.

xvii. Mithas, S., \& Rust, R. T.,. (2016). How Information Technology Strategy and Investments Influence Firm Performance: Conjecture and Empirical Evidence. MIS quarterly, 40(1), 223-245. .

xviii. $\quad$ Monemi, R. N., Danach, K., Khalil, W., Gelareh, S., Lima, F. C., \& Aloise, D. J.. (2015). Solution methods for scheduling of heterogeneous parallel machines applied to the workover rig problem. Expert Systems with Applications, 42(9), 4493-4505.

xix. Porter, M. E. (1991). Towards a dynamic theory of strategy. Strategic management journal, 12(S2), 95-117. .

xx. Scherer, A. G., Palazzo, G., \& Seidl, D.,. . (2012). Legitimacy strategies in a globalized world: Organizing for complex and heterogeneous environments.

xxi. Schwager, A. L., Haack, A. K., \& Taha, S. A., (2014). Impaired flexibility in decision making in rats after administration of the pharmacological stressor yohimbine. Psychopharmacology, 231(20), 3941-3952.

xxii. Singh, T. P., \& Ahuja, I. S. (2017). Evaluating manufacturing performance through strategic total productive maintenance implementation in a food processing industry. International Journal of Productivity and Quality Management, 21(4), 429-442.

xxiii. Stuckler, D., Reeves, A., Karanikolos, M., \& McKee, M. (2015). The health effects of the global financial crisis: can we reconcile the differing views? A network analysis of literature across disciplines. Health Economics, Policy and Law, 10(1), 83-99.

xxiv. Tjader, Y., May, J. H., Shang, J., Vargas, L. G., \& Gao, N.,. (2014). Firm-level outsourcing decision making: A balanced scorecard-based analytic network process model. International Journal of Production Economics, 147, 614-623. .

xxv. Wahab, M. H. A.-A. A., Ismail, M., \& Muhayiddin, M. N... (2016). Factors Influencing the Operational Excellence of Small and Medium Enterprise in Malaysia. International Journal of Academic Research in Business and Social Sciences, 6(12), 285-297.

xxvi. Xue, Y., Liang, H., \& Boulton, W. R.,. (2008). Information technology governance in information technology investment decision processes: . Mis Quarterly, 67-96.

xxvii. Yalcinkaya, G., Calantone, R. J., \& Griffith, D. A., . (2007). An examination of exploration and exploitation capabilities: Implications for product innovation and market performance. Journal of International Marketing, 15(4), 63-93. . 